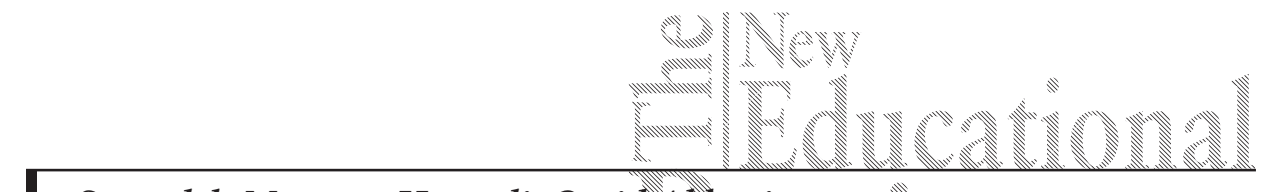

Seyyedeh Maryam Hamedi, Omid Akari. Seyyedeh Mina Hamedi

Iran

\title{
An Investigation into Extraverts' and Introverts' Speaking Anxiety in English Classes
}

DOI: 10.15804/tner.2015.41.3.12

\begin{abstract}
The presented study aimed at investigating the relationship between the extraversion level and speaking anxiety in the English as a Foreign Language (EFL) context on the one hand, and testifying the relationship between the extraversion degree and speech fluency and speech accuracy, on the other hand. To this end, 60 advanced university students, including 12 males and 48 females, participated in the study at the quantitative phase, and 28 of them, including 14 from the extraversion levels, and 14 from the introversion levels, were observed on their oral performance at the qualitative phase. Based on Spearman's Rank Order Correlation using SPSS in the quantitative section, the findings revealed a strong negative correlation between the extraversion level and public speaking anxiety, on the one hand, and a strong positive correlation between the extraversion degree and speech fluency in the qualitative phase, on the other hand. Speech accuracy revealed having no significant correlation with the extraversion degree. Indeed, extraversion and introversion seem to be the major personality differences that have attracted the attention of psycholinguists, in particular Dornyei (2005); henceforth, it would be worth clarifying the underlying characteristics of this construct to gain a more comprehensive view of these personality type indicators, respectively.
\end{abstract}

Keywords: extraversion, public speaking anxiety, speech fluency, speech accuracy 


\section{Introduction}

\subsection{Background}

Individual Differences (IDs) can have a consequential effect not only on the most important process underlying Second Language Acquisition (SLA), but also they may affect various learning styles and rates as well as inducing strengths and weaknesses in acquiring the mother tongue (Dornyei, 2005). Eysenck (1994) acknowledged that human beings differ from each other in numerous ways; however, some of these ways are of more importance to psychology than the others to be probed extensively, among which personality is of wider significance. Campbell, McCabe, Troup, and Davalos (2011) pointed out that exploring facets of personality and individual differences may be conducive to gaining a better insight into the cognitive system; however, learner differences in second or foreign language learning can be interpreted not only by depending on the cognitive factors, such as language aptitude and learning style, but also by hinging upon affective factors, such as motivation and anxiety (Tianjian, 2010).

Accordingly, extraversion and introversion (E-I) are the major personality differences that have attracted the attention of psycholinguists, in particular Dornyei (2005).Therefore, it would be worth clarifying the underlying characteristics of this construct to gain a more comprehensive view of thess personality type indicators, respectively.

Furnham (1990) highlighted the existence of numerous distinct common-sense relationships between E-I and language use to the point that with relative ease, a reliable measure of this trait can be produced. For instance, regarding the oral production,extraverts are characterized by their talkativeness and fewer pauses, whereas introverts are marked by tending to utilize more formal speech with more careful grammatical constructions (Dornyei, 2005); however, acquisition and fluent production of foreign languages can be highly affected by Foreign Language Anxiety (FLA), too (Dewaele, Petrides, \& Furham, 2008; Andrade\& Williams , 2008). Many students feel more anxious and distressed in the foreign language (FL) class than in any other classes (Campbell \& Ortiz, 1991; Horwitz, Horwitz, \& Cope, 1986; MacIntyre \& Gardner, 1989), and their anxiety seems to stem predominantly from the speaking situation (Koch \& Terrell, 1991; MacIntyre \& Gardner, 1994; Price, 1991).

Consequently, since speech is one of the most natural and common ways of exchanging information and it is widely considered as one of the prominent skills in foreign language learning classes, contributing to the opening of numerous 
L2 discussions, maintenance of pairwork and groupwork, and promoting higher chances of self-expression.

Indeed, in as much as the awareness of these personality differences, as useful predictors for L2 achievement, can make a big contribution to second/foreign language teachers' performance for adopting wiser and due strategies in dealing with individual differences, psycholinguists have mostly addressed the impact of these personality dimensions on the learner's natural communicative oral performance (e.g., Socan \& Bucik, 1998; Dewaele \& Furnham, 1999, 2000). Yet, it seems that conducting research on the relationship between these personality traits and the learner's anxiety level while speaking English, in a mixed qualitative and quantitative method, has been comparatively neglected; henceforth, the presented study aimed at examining the relationship between students' extent of extraversion and their speaking anxiety at a quantitative phase, and analyzing the speech fluency and accuracy across a number of extraverts and introverts at a qualitative phase. In sum, it focused on investigating the relationship between the extroversion level and the speech anxiety level in foreign language classes. In other words, the study attempted to examine the relationship between E-I and speaking anxiety in a mixed method approach.

\subsection{Research Questions}

The following research questions were posed and investigated in the study:

1. Is there any significant relationship between students' speaking anxiety level and their extent of extraversion?

2. Is there any significant difference regarding the speech anxiety across highly extraverted, moderately extraverted, moderately introverted, and quite introverted individuals?

3. Is there any significant relationship between the extraversion level and speech fluency?

4. Is there any significant relationship between the extraversion level and speech accuracy?

\section{Literature Review}

Eysenck and Eyenck (1975), and Myers (1962) demonstrate that extraverts tend to be open to strangers and get socially mixed whereas introverts are likely to keep aloof and tend not to keep a high profile. "Extraverts have found to be more talkative in triads or groups (Bem \& Allen,1974; Shaw, 1976 as cited in Thorne, 1987, 
p. 718), but not necessarily in dyads where findings are inconsistent" (Campbell \& Rushton, 1987 as cited in Thorne, 1987, p. 718). Based on Jung's personality typology $(1923,1976)$, extraverts are generally outgoing, direct, energetic, and sociable and introverts are more reticent, bashful, thoughtful, sensitive, and inscrutable. Besides, he believes that extraverts prefer constructing a more inclusive and common space, whereas introverts tend to take a more exclusive and individual space. In fact, Gale (1969) defines extraverts as the ones who are more restless and energetic in restricted environments.

Extraverts have proved to have outperformed introverts in faster doing of more complex tasks, which calls for more response competition; however, the easiness of the task or the task which involves little response competition would deprive them of the favored advantage (Eysenck, 1974, 1976).

The distinction between extraverts and introverts regarding the complexity of the task has been paid special attention by numerous researchers (e.g., Bone, 1971; Mclaughlin \& Eysenck 1967; Shanmugan \& Santhanam, 1964).For instance, Eysenck (1976) assumed an inverse relationship between the optimum level of arousal and the task difficulty. Eysenck's theory is in line with the Yerkes-Dodson law, which claims a curvilinear (inverted U) relationship between the level of "drive" and performance (Socan \& Bucik, 1998).

Socan and Bucik (1998) confirmed that since the middle level of arousal results in optimum performance, extraverts' performance on mental speech tasks should consequently be better in "highly arousing" conditions, while introverts would favor "low arousing " conditions. Besides, Campbell, McCabe, Troup, and Davalos (2011) confirmed that there is an inextricable relationship between E-I and various levels of arousal to the stimuli based on differences in the activation of the ascending reticular activating system. Dewaele and Furnham (1999) explained that introverts are more susceptible to higher pressure conditions since the arousal level exceeds their optimum level, which in turn hampers the automaticity of their oral production; therefore, they slide back to controlled serial processing which would result in slower speech production, hesitation, and more errors. In addition, Dewaele and Furnham (2000) attributed the inability of introverts to produce longer utterances to their lack of sufficient short-term memory capacity, which would attenuate their speech fluency. 


\section{Methodology}

This section contains detailed information about the methodological implementation of the current study, the purpose of which is to assess two dimensions of the individual personality traits, among which extraversion and introversion and speaking anxiety have been exclusively taken into account as the focus of this study.

\subsection{Participants}

A sample of 60 advanced English students, studying at Imamreza University of Mashhad, with the average age of 19.22, ranging from 18 to 25, comprising 12 males and 48 females, participated in this study with no expectation of rewards in the end. Besides, in the qualitative phase, 28 freshman females' speech, including 14 extraverts and 14 introverts, were audio recorded to analyze their speech fluency and accuracy extensively.

\subsection{Instruments}

The instruments employed in the study included two questionnaires, with one containing items related to their level of extraversion, and the other containing items related to their public speaking anxiety.

\subsubsection{Myer-Briggs Type Indicator (MBTI) test}

The standardized Myer-Briggs Type Indicator (MBTI) test was utilized in this study, consisting of 15 multiple choice questions with two choices of a, b devoted specifically to assessing the overall level of extraversion-introversion in the individuals. This scale produces a possible range of scores from zero to fifteen, based on which the learners were categorized into four main dichotomies of: 1. Quite introverted (if they scored six and below) 2. Moderately introverted (seven or eight) 3. Moderately extraverted (between nine and twelve), and 4. Quite extroverted (thirteen to fifteen), depending on the MBTI guidelines. Cronbach's alpha was computed with the score exhibiting the reliability coefficient of .79 for the extraversion and introversion traits.

\subsubsection{Public speaking classroom anxiety scale}

For the purpose of this study, Public Speaking Classroom Anxiety Scale (PSCAS) was utilized. The questionnaire consists of 17 items, each on a 5-point scale ranging from strongly agree (scale point 5 ) to strongly disagree (scale point 1). The internal consistency coefficient of the completed questionnaires turned out to be .84 . 


\subsection{Data Collection}

The survey was conducted in the first semester of the 2013/2014 academic year. To find out the relationship between extraversion and public speaking anxiety, two questionnaires were administered to 60 university students, one containing the single scale for speaking anxiety and the other for the extraversion level. Both were administered at the beginnings of normal English classes, with the former taking about 12 minutes on average, and the latter about 8 minutes. Furthermore, in an attempt to study the differences between extraverts and introverts regarding their oral production in the EFL classroom context, 28 females' speech, at the advanced proficiency level based on the administered TOEFL exam score, comprising 14 from highly extraverted and moderately extraverted, and 14 from quite introverted and moderately introverted extraversion scale, were audio recorded during their panel discussion classes in five successive sessions each lasting 90 minutes.

Depending on the university curriculum, the students had to pass these fourcredit panel discussion classes for two successive semesters as a compulsory course to gain the chance of making their way to the higher levels. To this end, the learners were provided with opportunities for having free interpersonal natural English discussions on various agreed everyday topics, based on which they were meticulously scored on both their accuracy and fluency by their professor. Henceforth, their discussions were recorded in a relatively stressful interpersonal situation. In all seven and a half hours of speech they were recorded, each having the opportunity of speaking for about 16 minutes during these sessions. Finally, for further analyses, the recordings were transcribed by the researcher into orthographical English. These transcriptions were then coded at the word level based on their structural nature and for possible lexical or morphological errors.

\subsection{Data Analysis}

After collecting the data, it was entered into and processed with SPSS program. Considering that the aim of this study was mainly two-fold, firstly it aimed at investigating the relationship between extraversion and public speaking anxiety and secondly, it attempted at testifying the significant differences across the four dichotomies of the extraversion scale regarding their speech anxiety level, the Spearman correlation for the first and Kruskal-Wallis for the second were computed. Finally, to specify the location of differences between pairs of groups (highly extraverted, moderately extraverted, moderately introverted, quite introverted), the Siegel \& Castellan inequality formula was utilized. 


\section{Results and discussion}

To testify the relationship between the extent of extraversion and the speaking anxiety (SA), the nonparametric Spearman rank-order correlation coefficient was computed. The relationship between extraversion (as measured by the MBTI) and public speaking anxiety (as measured by PSCAS) was investigated using the Spearman rank-order correlation coefficient. Preliminary analyses were performed to ensure there is no violation of the assumptions of normality, linearity and homoscedasticity. There was a strong, negative correlation between the two variables, rho $=-.94, n=60, p<.0005$, with high levels of extraversion associated with lower levels of speaking anxiety. Besides, the coefficient of determination of $88.36 \%$ was calculated to determine the extent of the shared variance between the two variables, which is quite a considerable amount of variance.

In order to detect the differences across the four dichotomies, with the highly extraverted ( $\mathrm{N}=7)$ accounting for $11.7 \%$, moderately extraverted $(\mathrm{N}=22)$ comprising $36.7 \%$, moderately introverted $(\mathrm{N}=9)$ including $15 \%$, and quite introverted $(\mathrm{N}=22)$ involving $36.7 \%$ of the total population, the nonparametric Kruskal-Wallis test was conducted (Table 1).

Table 1. Kruskal-Wallis Test

\begin{tabular}{lcrc}
\hline Ranks & & & \\
\hline & Group & N & Mean Rank \\
\hline SA & 1 & 22 & 49.50 \\
& 2 & 9 & 33.83 \\
& 3 & 22 & 18.57 \\
& 4 & 7 & 4.00 \\
\cline { 2 - 4 } & Total & 60 & \\
\hline
\end{tabular}

\begin{tabular}{lc}
\hline${\text { Test } \text { Statistics }^{a, b}}^{b^{2}}$ & SA \\
\hline Chi-Square & 52.884 \\
\hline Df & 3 \\
\hline Asymp. Sig. & .000 \\
\hline
\end{tabular}


Table 2 shows the median speaking anxiety values for each group

Table 2. Speaking Anxiety

\begin{tabular}{lcc}
\hline Group & $\mathbf{N}$ & Median \\
\hline 1 & 22 & 79.0000 \\
\hline 2 & 9 & 57.0000 \\
\hline 3 & 22 & 47.5000 \\
\hline 4 & 7 & 27.0000 \\
\hline Total & 60 & 53.0000 \\
\hline
\end{tabular}

In fact, the Kruskal-Wallis Test revealed a statistically significant difference in the speaking anxiety levels across three different extraversion groups (Gp1, $n=22$ : quite introverted, Gp2, $n=9$ : moderately introverted, Gp3, $n=22:$ moderately extraverted, $\mathrm{Gp} 4, \mathrm{n}=7$ : highly extraverted ), $\chi^{2}(3, n=60)=52.88, p=.000$. As a result, the quite introverted group obtained a higher median score $(M d=$ 79) compared to the other three groups, based on which the recorded median value of the moderately introverted is $\mathrm{Md}=57$, moderately extraverted $\mathrm{Md}=$ 47 , and highly extraverted $M d=27$. Therefore, speaking anxiety appears to take a decreasing trend in as much as the extraversion level is increasing. In other words, the more extraverted one is, the lower speaking anxiety one experiences. In fact, the result of the presented study is consistent with the previous studies by Matthews and Deary (1988), who found that introverts were more anxious and less stress-resistant.

To specify which of the groups are statistically and significantly different from one another, a nonparametric post-hoc comparison between the groups (Siegel \& Castellan, 1988, p. 213) was made. Depending on the Siegel \& Castellan inequality formula for a nonparametric post hoc test, the findings revealed significant results for the differences between the mean values of $\mathrm{Gp}$ 1: quite introverted (49.50) and the mean value of $\mathrm{Gp} 3$ : moderately extraverted (18.57), which exceeds the rate of 13.83, Gp 1: quite introverted (49.50) and Gp 4: highly extraverted (4.00), exceeding the rate of 19.99, and finally between $\mathrm{Gp} 2$ : moderately introverted (33.83) and Gp4: highly extraverted (4.00), exceeding 23.18. Hence, insignificant differences were found between other pairwise group comparisons of quite introverted and moderately introverted, moderately extraverted and moderately introverted, moderately extraverted and quite extraverted ones. To sum up, the differences between the two levels of extraversion, the two levels of introversion, and the moderate levels of both, were not statistically significant. 
To answer the third research question, regarding the relationship between extraversion level and speech fluency, the oral production of 28 participants were audio recorded and meticulously transcribed, coded, and scored with regard to Yaruss's (1998) guidelines for speech fluency assessment, based on which they were scored for repetitions, prolongations, long pauses, blocks, revisions, and fillers. Consequently, the relationship between the extraversion degree and speech fluency was investigated using the Pearson product-moment correlation coefficient. Preliminary analyses were performed to ensure there was no violation of the assumptions of normality, linearity and homoscedasticity. There was a strong, positive correlation between the two variables, $r=.64, n=28, p<.0005$, with higher levels of extraversion associated with higher levels of speech fluency. Besides, the coefficient of determination of $40.96 \%$ was calculated to determine the extent of the shared variance between the two variables, which is quite a considerable amount of variance.

This finding is in line with Dewaele and Furnham's (1999) study, in which they found a strong positive correlation between the extraversion degree and the speech rate, since the introverts' speech exhibited more hesitation markers such as 'er' and break-downs. Besides, their findings suggest that more introverted speakers hesitate more when they are under pressure, which would assert the presented research findings on the relationship between speaking anxiety and the extraversion level. The findings also match Dornyei's (2005) results asserting that extraverts are better than introverts at speech fluency.

In response to the fourth question regarding their speech accuracy to be scored at the morpholexical level, their morphological and lexical errors were calculated. Based on Dewele and Furnham (2000), at the morphological level, the violation of gender and number, and concerning verbs, violations of tense and aspect, mode and person, were taken into account, whereas at the lexical level, the lexical violations including lexical inventions (non-existing vocabulary) and words superficially right, but not fitting in the context were taken into account. Finally, the relationship between the extraversion degree and speech accuracy was investigated with the use of the Pearson product-moment correlation coefficient. Preliminary analyses were performed to ensure there is no violation of the assumptions of normality, linearity and homoscedasticity. There was an insignificant positive correlation between the two variables, $r=.21, n=28$, revealing no significant relationship between the extraversion level and speech accuracy, which is consistent with Dewele and Furnham's (2000) findings on the speech accuracy and extraversion level investigation. 


\section{Delimitations}

Since numerous variables may be found to be affecting ESL proficiency, and consequently the L2 oral production, it is beyond the scope of the presented study and also extremely difficult to consider all the potential variables that might account for the differences in how L2 learners develop higher proficiency in the areas of speaking.

Therefore, the focus of the presented study was to investigate the relationship between E-I and L2 verbal communicative language ability. Henceforth, further research on the impact of other confounding variables, including teachers' effectiveness, motivation, gender, learning styles, willingness to communicate, and language learning strategies on developing L2 oral skills across extroverts and introverts, is required.

Furthermore, the presented study aimed at merely addressing one language skill (speaking) exclusively; therefore, further studies are recommended on the role of this personality type indicator on the L 2 achievement in the area of listening, reading, and writing, as well.

\section{Conclusion}

The findings of the study suggest that there is a strong negative correlation between the extent of extraversion and public speaking anxiety. In other words, the more extraverted one is, the less public speech anxiety one experiences. Moreover, the study reveals that there were significant differences regarding speech anxiety between the pairs of highly extraverted and quite introverted, highly extraverted and moderately introverted, and finally moderately extraverted and quite introverted groups. Besides, a strong positive correlation was found between the extraversion level and speech fluency. Finally, no significant relationship was detected between the extraversion degree and speech accuracy.

\section{References}

Andrade, M., \& Williams, K. (2009). Foreign language learning Anxiety in Japanese EFL university classes: Physical, emotional, expressive, and verbal reactions. Sophia Junior College Faculty Journal, 29, 1-24.

Bone, R.N. (1971).Interference, extraversion and paired-associates learning. British Journal of Socialand Clinical Psychology, 10, 284-285. 
Campbell, A.M., Davalos, D.B., McCabe, D., \& Troup, L. (2011). Executive functions and extraversion. Personality and Individual Differences, 51, 720-725.

Campbell, C.M., \& Ortiz, J. (1991).Helping students overcome foreign language anxiety: A foreign language anxiety workshop. En E.K. Horwitzy D.J. Young (Eds.), Language anxiety: From theory and research to classroom implications (pp. 153-168). Englewood, NJ: Prentice Hall.

Dörnyei, Z. (2005). The psychology of the language learner: Individual differences in second language acquisition. Mahwah, NJ: Lawrence Erlbaum.

Dewaele, J.M., Petrides, K.V., \& Furnham, A. (2008). The effects of trait emotional intelligence and sociobiographical variables on communicative anxiety and foreign language anxiety among adult multilinguals: A review and empirical investigation. Language Learning, 59, 911-960.

Dewaele, J.M. \& Furnham, A. (1999). Extraversion: the unloved variable in applied linguistic research. Language Learning, 19 (3), 509-544.

Dewaele, J.M. \& Furnham, A. (2000). Personality and speech production: a pilot study of second language learners. Personality and Individual Differences, 28, 355-365.

Eysenck, M.W. (1974). Age differences in incidental learning. Developmental Psychology, 10, 936-941.

Eysenck, H.J. (1976). The Measurement of Personality. Baltimore: University Park Press.

Eysenck, H.J.(1994). Personality: Biological foundations. In P.A. Vernon (Ed.)The neuropsychology of individual differences. London: Academic Press.

Eysenck, H.J., \& Eysenck, S.B.G. (1975).Manual of the Eysenck Personality Questionnaire (adult and junior).London: Hodder \& Stoughton.

Eysenck, H.J., Nias, D.K.B., \& Cox, D.N. (1982). Sport and personality. Advances in Behavior Research and Therapy, 4, 1-56.

Furnham, A. (1990). Language and personality. In H. Giles \& W. Robinson (eds.), Handbook of Language and Social Psychology (pp.73-95). Wiley, Chichester.

Gale, A. (1969). Stimulus hunger: Individual differences in operant strategy in a button-pressing task. Behavior Research and Therapy, 7, 265-274.

Horwitz, E.K., Horwitz, M.B., \& Cope, J.A. (1986). Foreign language classroom anxiety. Modern Language Journal, 70, 125-132.

Jung, C.G., (1923/1976). Psychological types. Bollingen Series XX Princeton, NJ: Princeton University Press.

Koch, A.S., \& Terrell, T.D. (1991).Affective reactions of foreign language students to natural approach activities and teaching techniques. En E.K. Horwitz y D.J. Young (Eds.), Language Anxiety: From Theory and Research to Classroom Implications (pp. 109-126). Englewood Cliffs, NJ: Prentice Hall.

MacIntyre, P.D., \& Gardner, R.C. (1994).The subtle effects of language anxiety on cognitive processing in the second language. Language Learning, 44, 283-305.

MacIntyre, P.D., \& Gardner, R.C. (1989). Anxiety and second language learning: Toward a theoretical clarification. Language Learning, 39, 251-275.

Matthews, G., \& Deary, I. (1998). Personality traits, Cambridge University Press, Cambridge. 
Mclaughlin, R.J., \& Eysenck, H.J. (1967). Extraversion, neuroticism and paired associate learning. Journal of Experimental Research in Personality, 2, 128-132.

Myers, LB. (1962). Manual: The Myers-Briggs Type Indicator. Princeton, NJ: Educational Testing Services.

Price, M.L. (1991). The subjective experience of foreign language anxiety: Interviews with highly anxious students. En E.K. Horwitz, y D.J. Young (Eds.), Language anxiety: From Theory and Research to Classroom Implications (pp. 101-108). Englewood Cliffs, NJ: Prentice-Hall.

Shanmugam, T.E., \& Santhanam, M.L. (1964). Personality differences in serial learning when interferenece is presented at the marginal visual level. Journal of the Indian Academy of Applied Psychology, 1 (1), 25-28.

Siegel, S. \& Castellan, N.J. (1988). Nonparametric statistics for the behavioral sciences. McGraHill, NY.

Socan \& Bucik (1998). Relationship between speed of information-processing and two major personality dimensions - extraversion and neuroticism. Personality and Individual Differences, 25, 35-48.

Thorne, A. (1987). The press of personality: A study of conversations between introverts and extraverts. Journal of Personality and Social Psychology, 53, 718-726.

Tianjian, W., (2010).Speaking anxiety: More of a function of personality than language achievement. Chinese Journal of Applied Linguistics, 33(5), 95-10.

Williams, K.E., \& Andrade, M.R. (2008). Foreign language learning anxiety in Japanese EFL university classes: Causes, coping, and locus of control. Electronic Journal of Foreign Language Teaching, 5(2),181-191.

Yaruss, J.S. ( 1998). Real-Time Analysis of Speech Fluency. Journal of Speech-Language Pathology, 7, 25-37.

Zuckerman, M.,(1983). Sensation seeking and sports. Personality and Individual Differences, 4, 285-293. 